\title{
Overview of the EOS Aura Mission
}

Mark R. Schoeberl, Anne R. Douglass, Ernest Hilsenrath, Pawan K. Bhartia, Reinhard Beer, Joe William Waters, Michael R. Gunson, Lucien Froidevaux, John C. Gille, John J. Barnett, Pieternel F. Levelt, and Phil DeCola

\begin{abstract}
Aura, the last of the large Earth Observing System observatories, was launched on July 15, 2004. Aura is designed to make comprehensive stratospheric and tropospheric composition measurements from its four instruments, the High Resolution Dynamics Limb Sounder (HIRDLS), the Microwave Limb Sounder (MLS), the Ozone Monitoring Instrument (OMI), and the Tropospheric Emission Spectrometer (TES). With the exception of HIRDLS, all of the instruments are performing as expected, and HIRDLS will likely be able to deliver most of their planned data products. We summarize the mission, instruments, and synergies in this paper.
\end{abstract}

Index Terms-Atmospheric composition, Aura, Earth Observing Sytem (EOS), remote sensing, satellites.

\section{INTRODUCTION}

$\mathbf{T}$ HE Earth Observing System (EOS) program began in the late 1980s with the selection of a large number of earth science instruments and interdisciplinary science teams. Originally conceived to fly on two very large platforms (EOS $\mathrm{A}$ and $\mathrm{B}$ ), budget constraints forced the redesign of the EOS program. EOS now consists of three core platforms, Terra, Aqua, and Aura and several smaller satellites such as SORCE and ICESAT. Terra (formerly EOS AM), launched in late 1999, focuses on land processes. Aqua (formerly EOS PM) focuses on the atmosphere's hydrological cycle and was launched in early 2002. Aura (Latin for breeze, formerly EOS CHEM) concentrates on atmospheric composition. Aura was launched July 15, 2004 into an ascending-node $705-\mathrm{km}$ sun-synchronous polar orbit with a $98^{\circ}$ inclination with an equator-crossing time of $13: 45 \pm 15 \mathrm{~min}$. The design life is five years with an operational goal of six years. Aura flies in formation about 15 min behind Aqua. The Cloud-Aerosol Lidar and Infrared Pathfinder Satellite Observation (CALIPSO, http://www-calipso.larc.nasa.gov) and Cloudsat (http://cloudsat.atmos.colostate.edu), to be launched together in April 2006 [22] will fly a few minutes behind Aqua. This group of satellites, including the CNES PARASOL satellite (http://smsc.cnes.fr/PARASOL/GP_mission.htm) which was launched in December 2004, and the ESSP Orbiting Carbon Observatory (OCO, http://oco.jpl.nasa.gov),

Manuscript received April 29, 2005; revised August 1, 2005.

M. R. Schoeberl, A. R. Douglass, E. Hilsenrath, and P. K. Bhartia are with the NASA Goddard Space Flight Center, Greenbelt, MD 20771 USA (e-mail: mark.r.schoeberl@nasa.gov).

R. Beer, J. W. Waters, M. R. Gunson, and L. Froidevaux are with the Jet Propulsion Laboratory, Pasadena, CA 91109 USA.

J. C. Gille is with the University of Colorado, Boulder, CO 80309 USA.

J. J. Barnett is with the Oxford University, Oxford, OX1 2JD, U.K

P. F. Levelt is with the Royal Dutch Meteorological Institute (KNMI), KS/AS, 3730 AE De Bilt, The Netherlands.

P. DeCola is with the National Aeronautics and Space Administration, Washington, DC, 20546 USA.

Digital Object Identifier 10.1109/TGRS.2005.861950

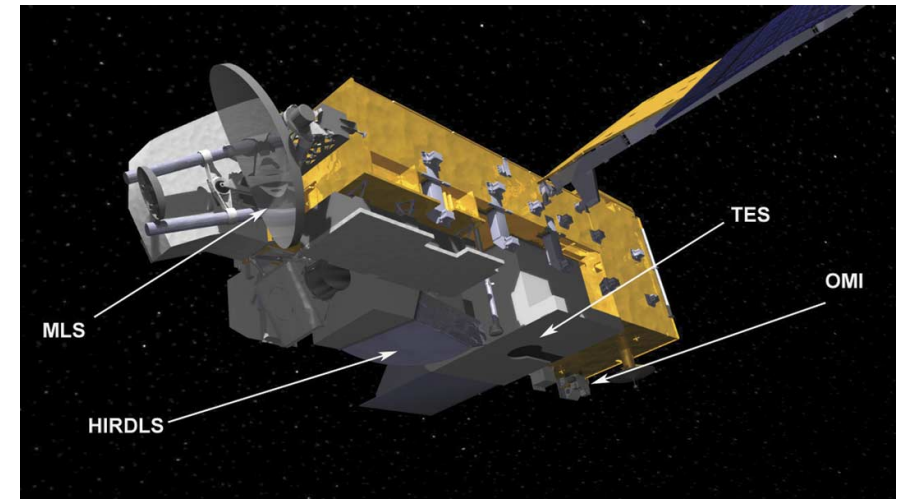

Fig. 1. Model of the Aura spacecraft showing the location of the four instruments, HIRDLS, MLS, OMI, and TES.

TABLE I

AURA INSTRUMENTS AND MEASUREMENTS

\begin{tabular}{|c|c|c|c|c|}
\hline Acronym & Name & Instrument PI & Constituent & Instrument Description \\
\hline HIRDLS & $\begin{array}{l}\text { High Resolution } \\
\text { Dynamics Limb } \\
\text { Sounder }\end{array}$ & $\begin{array}{l}\text { John Gille, National } \\
\text { Center for } \\
\text { Atmospheric } \\
\text { Research \& U. of } \\
\text { Colorado; } \\
\text { John Barnett, } \\
\text { Oxford University }\end{array}$ & $\begin{array}{l}\text { Profiles of T, } \mathrm{O}_{3}, \\
\mathrm{H}_{2} \mathrm{O}, \mathrm{CH}_{4}, \mathrm{~N}_{2} \mathrm{O}, \\
\mathrm{NO}_{2}, \mathrm{HNO}{ }_{3}, \mathrm{~N}_{2} \mathrm{O}_{5}, \\
\mathrm{CF}_{3} \mathrm{Cl}, \\
\mathrm{CF}_{2} \mathrm{Cl}_{2}, \mathrm{ClONO} \mathrm{N}_{2}, \\
\mathrm{Aerosols}^{2}\end{array}$ & $\begin{array}{l}\text { Limb IR filter radiometer } \\
\text { from } 6.2 \mu \text { to } 17.76 \mu \\
1.2 \mathrm{~km} \text { vertical resolution } \\
\text { up to } 50 \mathrm{~km} \text {. }\end{array}$ \\
\hline MLS & $\begin{array}{l}\text { Microwave Limb } \\
\text { Sounder }\end{array}$ & $\begin{array}{l}\text { Joe Waters, Jet } \\
\text { Propulsion } \\
\text { Laboratory }\end{array}$ & $\begin{array}{l}\text { Profiles of T, } \mathrm{H}_{2} \mathrm{O}, \\
\mathrm{O}_{3}, \mathrm{ClO}, \mathrm{BrO}, \mathrm{HCl}, \\
\mathrm{OH}, \mathrm{HO}_{2}, \mathrm{HNO}{ }_{3}, \\
\mathrm{HCN}, \mathrm{N}_{2} \mathrm{O}, \mathrm{CO}, \\
\text { cloud ice. }\end{array}$ & $\begin{array}{l}\text { Microwave limb sounder } \\
118 \mathrm{GHz} \text { to } 2.5 \mathrm{THz} \\
1.5-3 \mathrm{~km} \text { vertical } \\
\text { resolution }\end{array}$ \\
\hline OMI & \begin{tabular}{|l|} 
Ozone \\
Monitoring \\
Instrument
\end{tabular} & \begin{tabular}{|l|} 
Pieternel Levelt, \\
KNMI, Netherlands
\end{tabular} & $\begin{array}{l}\text { Column } \mathrm{O}_{3}, \mathrm{SO}_{2}, \\
\text { aerosols, } \mathrm{NO}_{2}, \mathrm{BrO}, \\
\text { OClO. } \mathrm{HCHO}, \\
\text { cloud top pressure, } \\
\mathrm{O}_{3} \text { profiles, UV-B. }\end{array}$ & $\begin{array}{l}\text { Hyperspectral nadir } \\
\text { imager, } 114^{\circ} \mathrm{FOV}, 270- \\
500 \mathrm{~nm}, 13 \times 24 \mathrm{~km} \\
\text { footprint for ozone and } \\
\text { aerosols }\end{array}$ \\
\hline TES & $\begin{array}{l}\text { Tropospheric } \\
\text { Emission } \\
\text { Spectrometer }\end{array}$ & $\begin{array}{l}\text { Reinhard Beer, } \\
\text { Mike Gunson, Jet } \\
\text { Propulsion } \\
\text { Laboratory }\end{array}$ & $\begin{array}{l}\text { Profiles of T, } \mathrm{O}_{3}, \\
\mathrm{NO}_{2}, \mathrm{CO}, \mathrm{HNO}_{3} \text {, } \\
\mathrm{CH}_{4}, \mathrm{H}_{2} \mathrm{O} .\end{array}$ & $\begin{array}{l}\text { Limb (to } 34 \mathrm{~km} \text { ) and } \\
\text { nadir IR Fourier } \\
\text { transform spectrometer } \\
3.2-15.4 \mu \\
\text { Nadir footprint } 5.3 \times 8.5 \\
\mathrm{~km}, \text { limb } 2.3 \mathrm{~km} \\
\end{array}$ \\
\hline
\end{tabular}

scheduled for launch in 2008, are referred to as the "A-Train." The measurements from Aura will be within $30 \mathrm{~min}$ of these other platforms. The A-Train can be thought of as an extended instrument package focusing on climate change.

Fig. 1 shows the Aura spacecraft and its four instruments (Table I): the High Resolution Dynamics Limb Sounder (HIRDLS), the Microwave Limb Sounder (MLS), the Ozone Monitoring Instrument (OMI), and the Tropospheric Emission Spectrometer (TES). These instruments were selected because of: 1) their complementary measurements; 2) their technological heritage; and 3) the new capabilities they bring to measuring the Earth's atmosphere. Below we describe the objectives and science strategy of the Aura mission. Fig. 2 graphically shows the vertical range of the various Aura measurements and the instrument that provides them. 


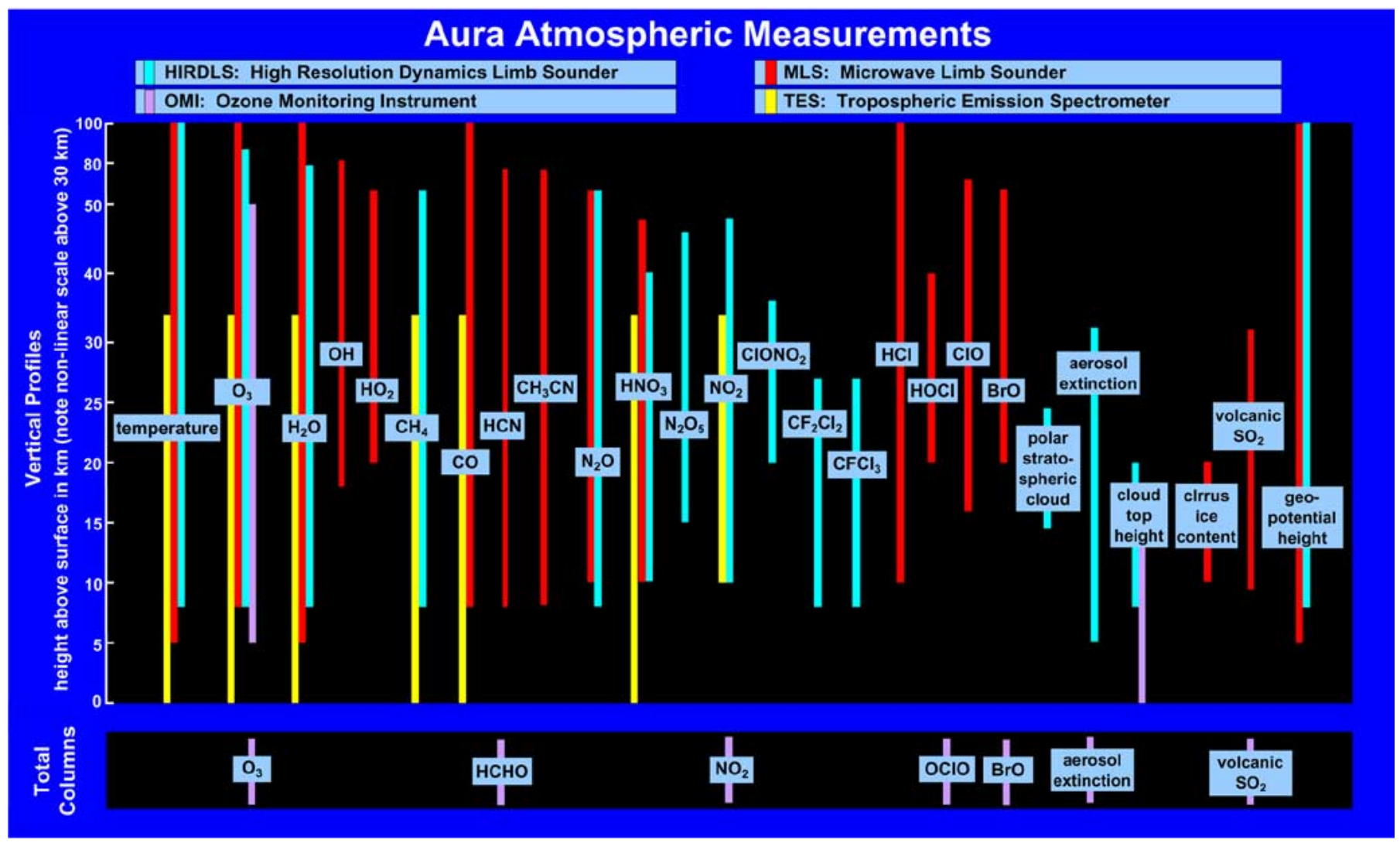

Fig. 2. Graphical representation of the various Aura instrument measurements and their height range based on prelaunch design. For HIRDLS, postlaunch capability is not yet demonstrated, but assuming that the instrument can be used, $50 \mathrm{~km}$ is the upper limit of the measurements. Column measurements are indicated in the lower part of the figure.

\section{SCIENCE ObJectives OF THE AURA Mission}

The objective of the Aura mission is to address three principal science questions: Is the ozone layer changing as expected? What are the processes that control tropospheric pollutants? What are the roles of upper tropospheric aerosols, water vapor, and ozone in climate change? The strategy Aura will employ in answering these questions is to obtain a very complete set of chemical observations at high vertical and horizontal resolution throughout the atmosphere (Table I). These measurements, when combined with measurements from field campaigns, other satellite measurements (e.g., Aqua measurements 15 min ahead of Aura on roughly the same ground track), and ground-based instrument data, should provide unprecedented insights into the chemical and dynamical processes associated with our atmosphere. In Section II-A we will discuss the individual questions and the Aura measurement approach.

\section{A. Is the Ozone Layer Changing as Expected?}

Total Ozone Mapping Spectrometer (TOMS) observations from 1978 to the present show strong decreases in ozone both at midlatitudes and in the polar regions. Although the Antarctic ozone hole growth has probably stopped and chlorine levels in the stratosphere are beginning to decline, very significant ozone depletions have occurred in the Arctic [4], [19]. As a result of international agreements, tropospheric chlorofluorocarbons concentrations have begun to decrease. HALOE (UARS) data show a flattening in the stratospheric chlorine reservoir concentrations [1] although an unambiguous decrease has not been

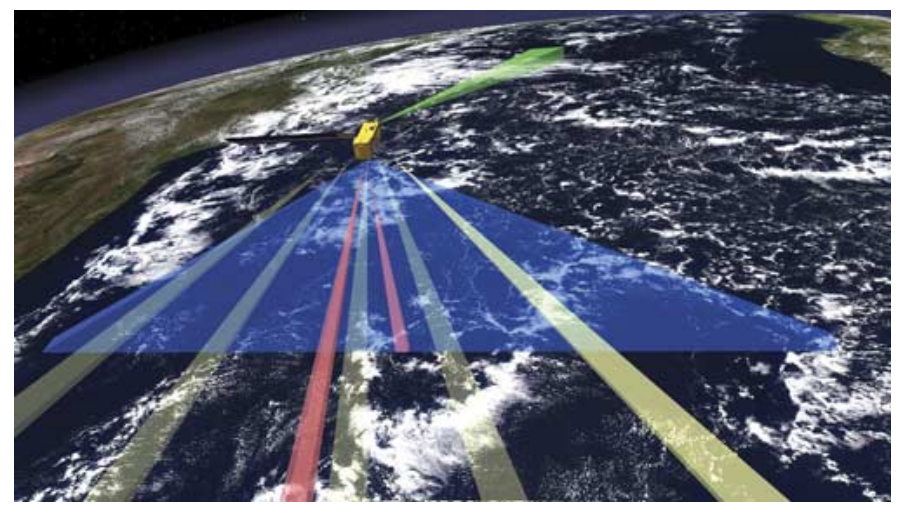

Fig. 3. Aura instrument fields of view are shown as colored beams. The viewer is looking at the back of the spacecraft. MLS performs forward limb sounding (green). OMI nadir measurements are indicated with the blue swath. TES limb and nadir measurements are shown in pink. HIRDLS measurements (five scan positions) are shown in yellow. TES and HIRDLS measurements are made in the antivelocity direction. Because of the Kapton blocking the HIRDLS optical system, HIRDLS will only be able to make measurements in the brighter yellow scan position.

detected. A decrease in chlorine should lead to recovery of the ozone layer, but the recovery in the polar region may be delayed by increases in greenhouse gases which would cool the stratosphere giving rise to more frequent and persistent polar stratospheric clouds (see Solomon [15] for a discussion of the chemistry of the ozone hole) and/or increase the water vapor in the stratosphere by warming the tropical tropopause [19]. In fact, stratospheric water vapor variations over the last decade cannot be accounted for by the secular trend in methane. As 
a result of the uncertainty in stratospheric trace gas measurements, current models used to assess the ozone layer do not agree on the timing of the recovery [19].

Recovery of ozone is the primary science question for the instruments HIRDLS, MLS, and OMI. The stratospheric measurements made by these instruments will permit a very complete assessment of the chemical processes controlling ozone. All three of the major radicals that destroy ozone $\left(\mathrm{ClO}, \mathrm{OH}\right.$, and $\left.\mathrm{NO}_{2}\right)$ will be made by HIRDLS and MLS along with the main reservoir gases, $\mathrm{HCl}, \mathrm{ClONO}_{2}$, and $\mathrm{HNO}_{3}$. In addition, the Aura instrument payload will make measurements of chlorine and nitrogen sources gases as well as long-lived tracers of motion, $\mathrm{N}_{2} \mathrm{O}, \mathrm{H}_{2} \mathrm{O}$, and $\mathrm{CH}_{4}$. OMI continues the column and profile ozone trends from TOMS/SBUV with higher horizontal resolution.

\section{B. What Are the Processes That Control Tropospheric Pollutants?}

Human activities have increased surface-level ozone concentrations, and decades of research and regulations now reveal that a global approach is required to understand sources and sinks of pollutants such as ozone and its precursors. Tropospheric ozone production occurs when volatile organic compounds (VOCs) and nitrogen oxides $\left(\mathrm{NO}_{\mathrm{x}}\right)$ are exposed to sunlight. Since the emissions of these ozone precursors are directly linked to today's urban and industrial lifestyle, reductions are both socially and economically costly. For this reason, policy makers have sought guidance from the scientific community in determining effective ways to meet health-based ozone standards or goals. The response of ozone to changes in $\mathrm{VOC}$ and $\mathrm{NO}_{\mathrm{x}}$ emissions can be quite complex and variable. Moreover, winds can transport both ozone and its precursors over large distances; and, as a result, exposure to elevated ozone can arise from both local and distant sources. The Aura mission is designed to produce the first global assessment of tropospheric ozone, its precursors, and controlling gases. The measurements from TES as well as measurements from OMI $\left(\mathrm{NO}_{2}\right.$, ozone, and aerosols) combined will provide important data on these processes.

\section{What Are the Roles of Upper Tropospheric Aerosols, Water Vapor, and Ozone in Climate Change?}

The importance of the upper troposphere/lower stratosphere (UT/LS) in chemistry and climate problems is well stated in a number of international assessment documents, e.g., [8]. Within the context of chemical problems one of the largest uncertainties is how much ozone and odd nitrogen is supplied to the troposphere from the stratosphere [7]. Even estimates of the cross tropopause flux of ozone from the stratosphere are uncertain to within $15 \%$ or greater [4], [19]. There are fundamental climate change questions related to moistening or drying of the upper troposphere as convective activity changes. For example, it is now understood that the outgoing infrared radiative flux of the Earth is strongly influenced by upper tropospheric/lower stratospheric water vapor, aerosols, and ozone [8]. On decadal time scales, signals from greenhouse gas changes and signals from the changes in reactive constituents are intertwined and difficult to untangle. The tropopause is a complex internal boundary within the atmosphere related to both radiative and dynamical mechanisms. Because the concentrations of many trace gases vary greatly across the tropopause, changes in the UT/LS impact not only the radiative attributes of the atmosphere, but also the chemical environment.

The location and intensity of both tropical and midlatitude stratosphere-troposphere exchange is key to our ability to quantify the properties of the UT/LS. One of the major science questions Aura measurements will be needed to solve is the mystery of increasing stratospheric water vapor. Stratospheric water vapor concentrations are changing in ways that cannot be accounted for by increases in methane, the major in situ source of water vapor in the stratosphere. A number of hypothesis suggest that changes in the freeze-dry mechanism at the tropical tropopause are producing an increase in water transport into the stratosphere. Untangling the complex freeze-dry mechanism of the tropical tropopause will be one of the goals of the Aura science team. Relative to the upper troposphere/lower stratosphere dynamics and chemistry, Aura instruments will make key measurements of ozone, water vapor, ice particles, and long-lived trace gases that will give lead to a better understanding of the dynamics and chemistry of that region. Especially important to the measurements of the UT/LS is HIRDLS, which can make high vertical resolution measurements of the atmospheric limb.

\section{SPACECRAFT AND INSTRUMENT DESCRIPTIONS}

The Aura spacecraft is designed for a six-year lifetime. The spacecraft orbits at $705 \mathrm{~km}$ in a sun-synchronous orbit $\left(98^{\circ}\right.$ inclination) with a 1:45 P.M. equator crossing time. Aura limb instruments were all designed to observe roughly along the orbit plane; however, with the HIRDLS anomaly discussed below, HIRDLS observations will be off to the side of the Aura ground track. MLS is on the front of the spacecraft (the forward velocity direction) while HIRDLS, TES, and OMI are mounted on the nadir side. HIRDLS and TES make limb soundings observing backward while MLS will make limb soundings observing forward. OMI and TES make nadir soundings as shown in Fig. 3. The advantage of this instrument configuration was that each of the instruments could observe the same air mass within minutes.

\section{A. HIRDLS}

HIRDLS is a 21-channel infrared limb-scanning filter radiometer designed to make the measurements listed in Table I [5], [20]. HIRDLS can also determine the altitude of polar stratospheric clouds and tropospheric cloud tops.

The HIRDLS instrument has a long heritage extending back to Nimbus-6, and was designed to obtain profiles over the entire globe, including the poles, both day and night. Complete Earth coverage (including polar night) could be obtained in $12 \mathrm{~h}$. HIRDLS was designed to achieve high horizontal resolution using commandable azimuth scans which, in conjunction with a rapid elevation scan, would provide profiles up to $3000 \mathrm{~km}$ apart in an across-track swath. The primary design advantage of HIRDLS over previous infrared limb instruments (LIMS, SAMS, ISAMS, CLAES) was its high vertical and horizontal resolution which extends from the upper troposphere throughout the stratosphere.

Current Status: After launch, activation of the HIRDLS instrument immediately revealed that something was blocking 
the optical path so that only a small portion of the aperture could view the Earth's atmosphere. Engineering studies of the engineering model suggested that a piece of thermal blanketing material ruptured from the back of the instrument during the explosive decompression of launch. This material now covers most of the scan mirror. Attempts to remove this material by moving the scan mirror failed. However, even with the $80 \%$ blockage, measurements at high vertical resolution can still be made at one scan angle. As of this writing, the HIRDLS principal investigators have demonstrated temperature and ozone retrievals with the instrument, and they believe that they can retrieve most of the other constituents as planned. HIRDLS will no longer have its designed horizontal coverage, and with only one side of the aperture available, HIRDLS will not be able to make measurements over the Antarctic.

\section{B. $M L S$}

MLS uses microwave emission to measure stratospheric temperature and constituents and upper tropospheric constituents (Table I) [17], [18]. MLS also has a unique capability to measure upper tropospheric water vapor in the presence of tropical cirrus, and also the cirrus ice content. Aura MLS continues the successful effort of UARS MLS [16] using advanced technology to provide new measurements. These measurements will be especially valuable for diagnosing the potential for severe loss of Arctic ozone during the critical period when abundances of stratospheric chlorine will still be high, and slight cooling of the stratosphere could exacerbate ozone loss due to chlorine chemistry. MLS is making the first global stratospheric measurements of $\mathrm{OH}$ and $\mathrm{HO}_{2}$, constituents that play an important role in stratospheric chemistry. The MLS instrument observes in spectral bands centered near five frequencies $[118 \mathrm{GHz}$ (temperature and pressure); $190 \mathrm{GHz}\left(\mathrm{H}_{2} \mathrm{O}, \mathrm{HNO}_{3}\right) ; 240 \mathrm{GHz}\left(\mathrm{O}_{3}\right.$ and $\mathrm{CO}) ; 640 \mathrm{GHz}\left(\mathrm{N}_{2} \mathrm{O}, \mathrm{HCl}, \mathrm{ClO}, \mathrm{HOCl}, \mathrm{BrO}, \mathrm{HO}_{2}\right.$, and $\left.\mathrm{SO}_{2}\right)$; and $2.5 \mathrm{THz}$ (primarily for $\mathrm{OH})]$.

The MLS instrument aboard UARS has demonstrated the MLS capability of measuring upper tropospheric water vapor profiles [12], [13], knowledge of which is essential for understanding climate variability and global warming but which previously has been extremely difficult to observe reliably on a global scale. MLS is unique in its ability to provide these measurements in the presence of tropical cirrus, where important processes affecting climate variability occur. MLS also provides unique measurements of cirrus ice content. The simultaneous MLS measurements of upper tropospheric water vapor, ice content, and temperature, under all conditions and with good vertical resolution, will be of great value for improving our understanding of large-scale meteorological systems (such as El Niño) affecting the distribution of atmospheric water, climate variability, and tropospheric-stratospheric exchange. The simultaneous measurements of dynamical tracers $\mathrm{CO}$ and $\mathrm{N}_{2} \mathrm{O}$ enhance the value of this dataset by helping identify stratospheric or tropospheric source regions of the air masses being observed.

Current Status: The MLS instrument was turned on shortly after launch because there is no requirement for outgassing, and the MLS team was able to produce data within 15 days of launch. Fig. 4 shows Antarctic $\mathrm{HCl}$ measurements as they evolved during the break up of the Antarctic vortex. MLS is discussed in more detail in [18]. Fig. 5 shows the tropical water vapor "tape recorder" [11] as seen by MLS. The instrument has shown no problems and is operating flawlessly, and the data are currently available on the Goddard Distributed Active Archive.

\section{C. $O M I$}

The OMI instrument is a contribution of the Netherlands's Agency for Aerospace Programs (NIVR) in collaboration with the Finnish Meteorological Institute (FMI) to the EOS Aura mission. OMI will continue the TOMS record for total ozone and other atmospheric parameters related to ozone chemistry and climate [9]. OMI measurements will be highly synergistic with measurements from the other instruments on the EOS Aura platform. The OMI instrument employs hyperspectral imaging in a pushbroom mode to observe solar backscatter radiation in the visible and ultraviolet. The Earth will be viewed in 740 wavelength bands along the satellite track with a swath large enough to provide global coverage in 14 orbits (one day). The nominal $13 \times 24 \mathrm{~km}$ spatial resolution can be zoomed to $13 \times 13 \mathrm{~km}$ for detecting and tracking urban-scale pollution sources. The hyperspectral capabilities will improve the accuracy and precision of the total ozone amounts and will also allow for accurate radiometric and wavelength self-calibration over the long term. Aside from the measurements listed in Table I, the OMI instrument will distinguish between aerosol types, such as smoke, dust, and sulfates, and can measure cloud pressure and coverage, which provide data to derive tropospheric ozone. A combination of algorithms including TOMS version 7, differential optical Absorption Spectroscopy (DOAS), hyperspectral BUV retrievals, and forward modeling will be used together to extract the various OMI data products.

Current Status: After an outgassing and cool-down period, OMI began to produce data in October 2004. Fig. 6 shows an $\mathrm{NO}_{2}$ map produced by the OMI science team. Additional discussion of the OMI instrument is given by Levelt et al. [9].

\section{TES}

TES is a high-resolution infrared-imaging Fourier transform spectrometer with spectral coverage of $3.2-15.4 \mu \mathrm{m}$ at a spectral resolution of $0.025 \mathrm{~cm}^{-1}$, thus offering line-width-limited discrimination of essentially all radiatively active molecular species in the Earth's lower atmosphere [2], [3], [6], [21]. TES has significantly higher spectral resolution than the AIRS instrument being flown aboard EOS Aqua. TES was built with the capability to make both limb and nadir observations. In the limb mode, TES has a height resolution of $2.3 \mathrm{~km}$, with coverage from $0-34 \mathrm{~km}$. In the down-looking modes, TES has a spatial resolution of $0.53 \times 5.3 \mathrm{~km}$ with a swath of $5.3 \times 8.5$ $\mathrm{km}$. TES is a pointable instrument and can access any target within $45^{\circ}$ of the local vertical, or produce regional transects up to $885-\mathrm{km}$ length without any gaps in coverage. TES employs both the natural thermal emission of the surface and atmosphere and reflected sunlight, thereby providing day-night coverage anywhere on the globe. TES operates in a combination of limb and nadir mode (called global survey mode) every other. On alternate days, TES does special observations including "step and stare" mode and assessment of special targets like 

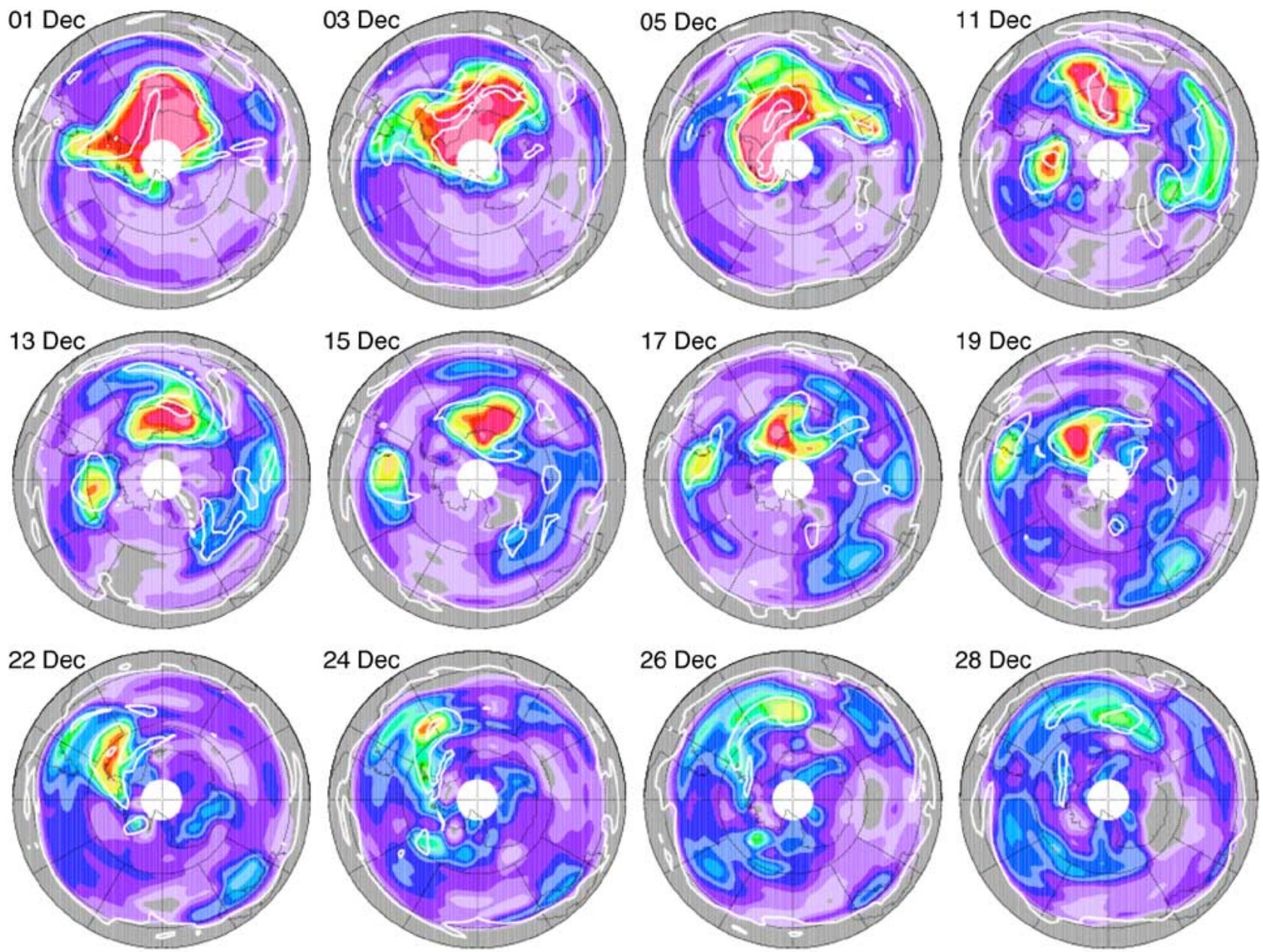

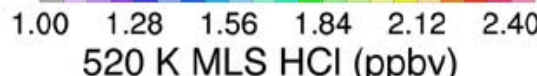

Fig. 4. These South Pole orthographic maps of $\mathrm{MLS} \mathrm{HCl}$ in the lower stratosphere $(520 \mathrm{~K}, 20 \mathrm{~km})$ detail the springtime breakup of the 2004 Antarctic vortex. The vortex broke into several fragments between December 5 and 11, and the evolution and erosion of those fragments is shown through late December, when only one weak fragment remains. After chlorine deactivation by early October, high vortex $\mathrm{HCl}$ and very strong $\mathrm{HCl}$ gradients across the vortex edge make it an excellent tracer of vortex evolution and morphology (from Manney et al. [10]).

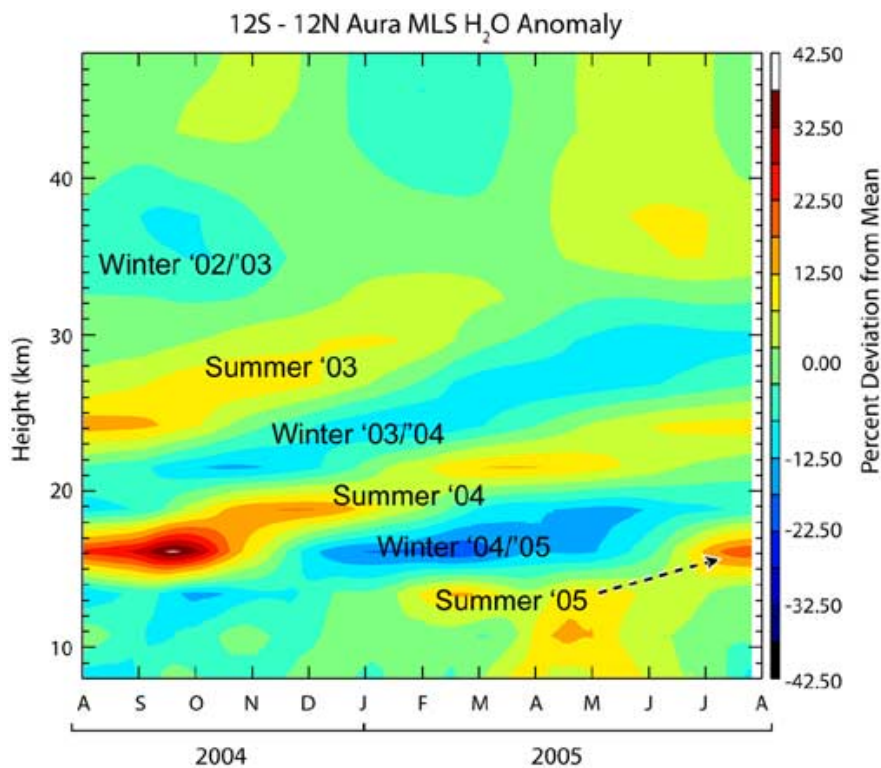

Fig. 5. Zonal mean tropical water vapor anomalies recorded by MLS showing the upward propagating dry and wet regions associated with the annual modulation of the tropical tropopause temperature. Date labels show when the bands were formed. (W. Read, JPL)

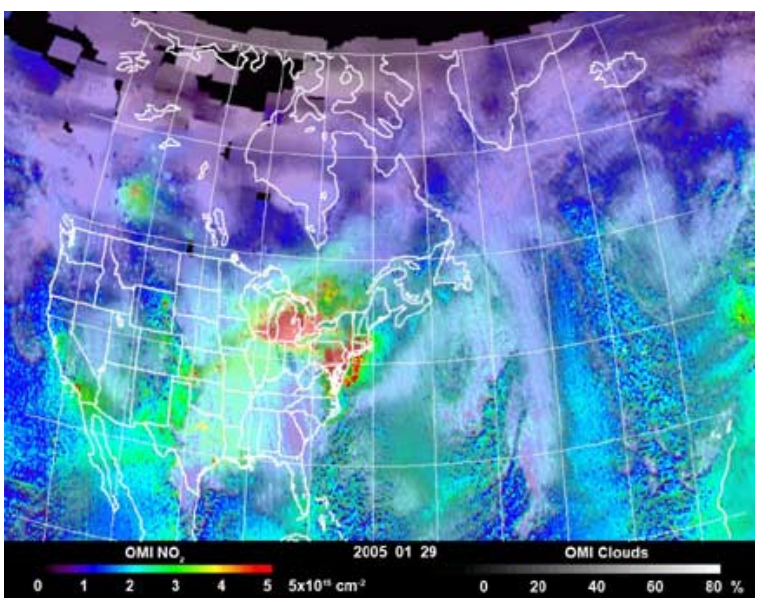

Fig. 6. $\mathrm{NO}_{2}$ measured by the OMI instrument on January 29, 2005. Red indicates high values, blue low values. Clouds are indicated in white. During this period, an air quality alert was issued for the state of Michigan (E. Bucsela, GSFC).

volcanoes. In the global survey mode, TES will provide global measurements of tropospheric ozone, and its photochemical precursors such as the other measurements are listed in Table I. 


\section{TES Level 3 Image (Tri_Surf/Linear): CO, Run $=2147$, Pressure $=700.0 \mathrm{hPa}$ Min Value $=10.5 \mathrm{ppb}$, Max Value $=315.2 \mathrm{ppb}$, Using Along Orbit Interpolated L2 Data}

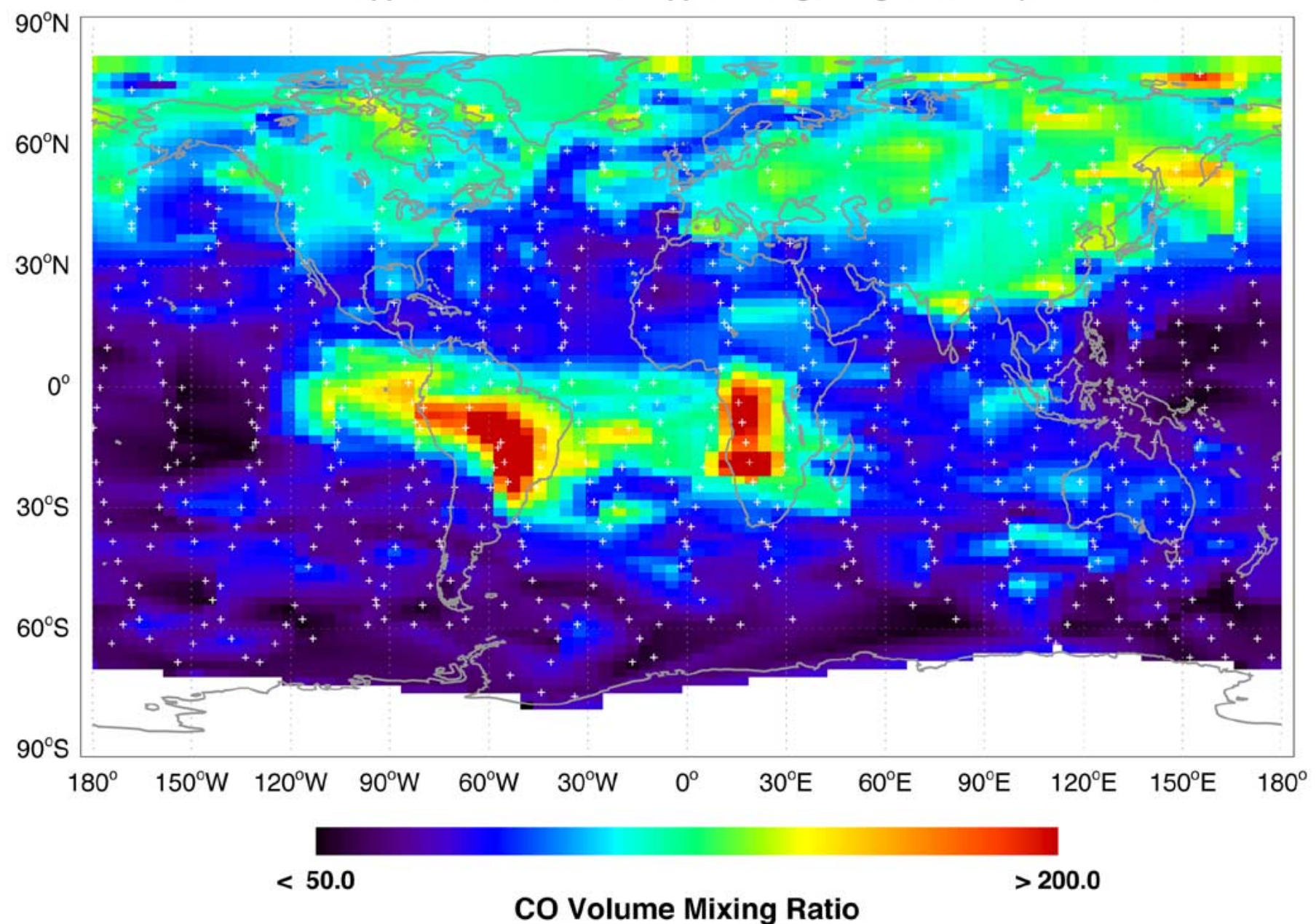

Fig. 7. TES CO at lower tropospheric pressure levels from their global survey mode. Measurements are made at the white crosses and interpolated to form a map. Northern hemispheric fossil fuel combustion sources and tropical biomass burning are evident sources of CO.

Because TES retrieves the entire spectrum from 3.2-15.4 $\mu \mathrm{m}$, the opportunity exists for TES to make measurements of a large number of other gases (i.e., ammonia and organics). Although the retrieval of these gases will be done in a research mode, the existence of this capability provides a resource for the tropospheric chemistry community.

Current Status: After launch, TES went through a lengthy outgassing procedure to minimize the ice buildup on their detectors. Initial results from TES are shown in Fig. 7. After several seven months of operation, the translator mechanism (which moves the reflecting surfaces of the spectrometer) began to show signs of bearing wear. The TES Instrument Team commanded the instrument to skip the limb sounding modes in May 2005. This will increase the bearing life of the translator and the life of the instrument. In any event, both HIRDLS and MLS provide limb measurement products redundant to TES. Further information on the TES instrument can be found in [3].

\section{E. Instrument Synergy}

MLS and HIRDLS will provide high vertical resolution profiles which are nearly simultaneous with the OMI observations, and which extend down to and below the tropopause. Thus, it will be possible to combine observations from these three instruments with meteorological data to produce effective separation of the stratospheric component of the total column ozone and thus provide an estimate of the tropospheric ozone column (sometimes called the residual). The residual can be compared to TES tropospheric profiles of $\mathrm{O}_{3}$. The combination of instruments will make it possible to understand the stratospheric and tropospheric contributions to $\mathrm{O}_{3}$ as well as the transport, physical, and chemical processes which effect their distributions.

Because HIRDLS and MLS are both observing the stratosphere, it will also be possible to better interpret photochemical processes involving constituents measured nearly simultaneously by HIRDLS and MLS. For example, $\mathrm{HNO}_{3}, \mathrm{OH}, \mathrm{NO}_{2}$, and $\mathrm{N}_{2} \mathrm{O}_{5}$ are related through their principal production and loss processes throughout the stratosphere. MLS will measure $\mathrm{OH}$ and $\mathrm{HNO}_{3}$. HIRDLS will measure $\mathrm{HNO}_{3}, \mathrm{NO}_{2}$, and $\mathrm{N}_{2} \mathrm{O}_{5}$. A second example involves chlorine species. Related gases are $\mathrm{HCl}, \mathrm{ClONO}_{2}, \mathrm{ClO}, \mathrm{NO}_{2}$, and $\mathrm{O}_{3}$ (which controls the relative concentrations of $\mathrm{HCl}$ and $\mathrm{ClONO}_{2}$ ). Here, $\mathrm{ClONO}_{2}, \mathrm{NO}_{2}$, and $\mathrm{O}_{3}$ are measured by HIRDLS, and $\mathrm{HCl}, \mathrm{ClO}$, and $\mathrm{O}_{3}$ are mea- 
sured by MLS. Combining such observations to make important tests of chemical processes on the global scale has been successful using CLAES, MLS, and HALOE on UARS.

\section{F. Synergy With Aqua, CALIPSO, and Cloudsat}

The Aura spacecraft is being flown 15 min behind the Aqua spacecraft, which means that many of the measurements on Aura will be made shortly after EOS Aqua. About 1 min behind the Aqua spacecraft, CloudSat and CALIPSO will make measurements of cloud properties using active radar and lidars, respectively. Because MLS is a limb sounder and is observing on the front of the Aura spacecraft, MLS measurements are effectively only $\sim 7$ min behind those being made by the Aqua nadir sounders. The MLS measurements of upper tropospheric water vapor and temperature in the limb [12] will be complementary to those made by AIRS and AMSU aboard Aqua.

\section{SUMMARY}

The EOS Aura mission was successfully launched on July 15, 2004. With the exception of HIRDLS, all of the instruments are functioning as designed, although to preserve instrument life, TES is now operating only in the nadir mode. Aura will provide the next level of measurements needed by the stratospheric and tropospheric community to advance the science and to answer the crucial broad questions: Is the stratospheric ozone layer recovering? How is the chemistry of the troposphere changing? What are the roles of upper tropospheric aerosols, water vapor, and ozone in climate change? Although there are only four instruments on Aura, they will provide the needed sets of measurements to answer these broad questions. Furthermore, the breadth of these instrument capabilities will allow us to use Aura data to attack future science questions.

For more information on the Aura platform and instruments, please refer to the web site http://aura.gsfc.nasa.gov. A prelaunch version of this paper was published in EOS [14].

\section{REFERENCES}

[1] J. Anderson, J. M. Russell, III, S. Solomon, and L. E. Deaver, "Halogen occultation experiment confirmation of stratospheric chlorine decreases in accordance with the Montreal Protocol," J. Geophys. Res., vol. 105, pp. 4483-4490, 2000.

[2] R. Beer, "TES on the Aura Mission: Scientific Objectives, Measurements, and Analysis Overview," IEEE Trans. Geosci. Remote Sens., vol. 44, no. 5, pp. 1102-1105, May 2006.

[3] R. Beer, T. A. Glavich, and D. M. Rider, "Tropospheric Emission Spectrometer for the Earth Observing Systems Aura satellite," Appl. Opt., vol. 40, pp. 2356-2367, 2001.

[4] A. Gettelman, J. Holton, and K. Rosenlof, "Mass fluxes of $\mathrm{O}_{3}, \mathrm{CH}_{4}$, $\mathrm{N}_{2} \mathrm{O}$ and $\mathrm{CF}_{2} \mathrm{Cl}_{2}$ in the lower stratosphere calculated from observational data," J. Geophys. Res., vol. 102, pp. 19 149-19 159, 1997.

[5] J. Gille, J. Barnett, J. Whitney, M. Dials, D. Woodard, A. Lambert, and W. Mankin, "The High Resolution Dynamics Limb Sounder (HIRDLS) experiment on Aura," in Proc. SPIE, vol. 5152, 2003, pp. 162-171.

[6] T. Glavich and R. Beer, "Tropospheric Emission Spectrometer for the Earth Observing System," in Proc. SPIE Conf. Infrared Technology XVII, San Diego, CA, Jul. 22-26, 1991.
[7] D. Hauglustaine et al., "MOZART, a global chemical transport model for ozone and related chemical tracers 2 . Model results and evaluation," J. Geophys. Res., vol. 103, pp. 28 291-28 335, 1998. 335.

[8] J. Houghton et al., Climate Change 2001: The Scientific Basis, IPCC, Intergovermental Panel on Climate Change. Cambridge, U.K.: Cambridge Univ. Press, 2001.

[9] P. F. Levelt et al., "The Ozone Monitoring Instrument," IEEE Trans. Geosci. Remote Sens., vol. 44, no. 5, pp. 1093-1101, May 2006.

[10] G. Manney et al., "EOS Microwave Limb Sounder observations of the Antarctic polar vortex breakup in 2004," Geophys. Res. Lett., vol. 32, no. L12811, 2005. DOI: 10.1029/2005GL022823.

[11] P. Mote et al., "An atmospheric tape recorder: The imprint of tropical tropopause temperatures on stratospheric water vapor," J. Geophys. Res., vol. 101, pp. 3989-4006, 1996.

[12] W. Read et al., "Upper tropospheric water vapor from UARS MLS," Bull. Amer. Meteorol. Soc., vol. 76, pp. 2381-2389, 1995.

[13] B. J. Sandor et al., "Seasonal behavior of tropical to midlatitude upper tropospheric water vapor from UARS MLS," J. Geophys. Res., vol. 103, pp. 25935-25947, 1998.

[14] M. R. Schoeberl et al., "Earth Observing Systems benefit atmospheric research," EOS, vol. 85, pp. 177-178, 2004.

[15] S. Solomon, "Stratospheric ozone depletion: A review of concepts and history," Rev. Geophys., vol. 37, pp. 275-316, 1999.

[16] J. W. Waters et al., "Stratospheric $\mathrm{ClO}$ and ozone from the Microwave Limb Sounder on the Upper Atmosphere Research Satellite," Nature, vol. 362, pp. 597-602, 1993.

[17] J. W. Waters et al., "The UARS and EOS Microwave Limb Sounder (MLS) experiments," J. Atmos. Sci., vol. 56, pp. 194-218, 1999.

[18] J. W. Waters et al., "The Earth Observing System Microwave Limb Sounder (EOS MLS) on the Aura satellite," IEEE Trans. Geosci. Remote Sens., vol. 44, no. 5, pp. 1075-1092, May 2006.

[19] WMO, "Scientific Assessment of Ozone Depletion: 2002," World Meteorol. Org., Geneva, Switzerland, Global Ozone Research and Monitoring Project, Rep. 47, 2002.

[20] J. Gille and J. Barnett, "Conceptual design of the High Resolution Dynamics Limb Sounder (HIRDLS) for the EOS Aura mission," Proc. SPIE, vol. 2830, pp. 190-201, 1996.

[21] T. Glavich and R. Beer, "Tropospheric Emission Spectrometer for the Earth Observing System," in Proc. SPIE, vol. 1540, 1991, pp. 148-159.

[22] G. L. Stephens et al., "The CloudSat Mission and the A Train," Bull. Amer. Meteorol. Soc., vol. 83, pp. 1771-1790, 2002.

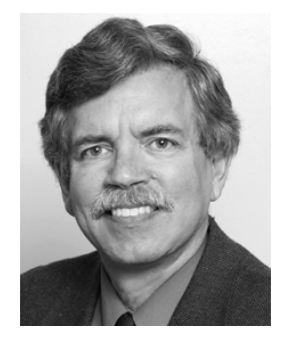

Mark R. Schoeberl was born in Iowa. He received the Ph.D. degree in physics from the University of Illinois, Urbana, in 1976.

$\mathrm{He}$ is currently an Atmospheric Scientist who specializes in stratospheric processes including wave dynamics, ozone depletion, and trace gas transport. Since the early 1980 s, he has worked at the NASA Goddard Space Flight Center, Greenbelt, MD, and is currently the Chief Scientist for the Earth Sciences Directorate and the EOS Aura Satellite Project Scientist. He has over 164 refereed publications and over 4500 citations in refereed atmospheric science journals.

Dr. Schoeberl is past President of the Atmospheric Sciences Section of the American Geophysical Union (AGU). He is a Fellow of the AGU (1996), the American Association for the Advancement of Science (1996), and the American Meteorological Society (1996). He was awarded Goddard's William Nordberg Memorial Award for Earth Sciences (1998), NASA's Exceptional Scientific Achievement Medal (1991), NASA's Outstanding Leadership Medal (1996), and Distinguished Service Award (2000). He was the 2004-5 Sigma Xi Lecturer for the AMS. As a member of the UARS Project, he shared the 2002 William T. Pecora Award for Understanding the Earth through Remote Sensing. 


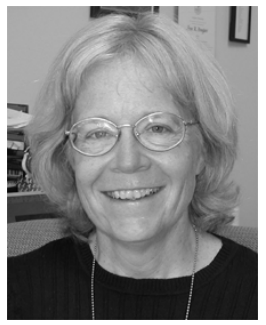

Anne R. Douglass received the Ph.D. degree in physics at Iowa State University, Ames, in 1980.

She has been with the NASA since the early1980s and is currently with the Goddard Space Flight Center, Greenbelt, MD. She is the Deputy Project Scientist for both the Upper Atmosphere Research Satellite (UARS) and Aura. Her research emphasizes the development and analysis of predictive models and the quantitative evaluation of satellite, aircraft, and ground-based observations. She has more than 90 referred publications and has extensive collaborations with researchers in universities and other agencies.

Dr. Douglass, as a member of the UARS Project, shared the 2002 William T. Pecora award for Understanding the Earth through Remote Sensing and is the winner of a Clare Boothe Luce Award for Women in Mathematics and Science. She is a member of the Steering Committee for NASA's Global Modeling Initiative. She is a Fellow of the American Meteorology Society and a member of Phi Beta Kappa.

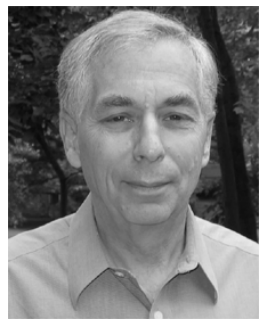

Ernest Hilsenrath was with NASA's Goddard Space Flight Center from 1965 to August 2005. He was Deputy Project Scientist for the EOS Aura mission and is Co-Principal Investigator for the Ozone Monitoring Instrument flying on Aura. In the 1970s, he developed a unique rocket payload to measure ozone profiles in the stratosphere and lower mesosphere. He also conducted ozone and water vapor measurements from rockets, balloons, and aircraft. He was the Principal Investigator of the Shuttle-borne SBUV instrument, flown eight times, to calibrate the SBUV/2 series of instruments in the NOAA polar orbiting satellites. He managed the Goddard Space Flight Center's Radiometric Calibration and Development Facility. The laboratory provides calibrations for national international satellite ozone instruments and developed the first UV/VIS limb scattering instruments to demonstrate, from the Space Shuttle, the ozone monitoring capability for NPOESS. He served on and chaired several international panels for atmospheric composition observations including NPOESS and Eumetsat. He is Chairman of the CEOS Cal/Val Working Group's Atmospheric Chemistry Subgroup. He has authored more than 50 papers on atmospheric composition and calibration/validation in peer-reviewed journals. He is currently a staff member at the University of Maryland Baltimore County, Baltimore, at the Joint Center for Earth Systems Technology.

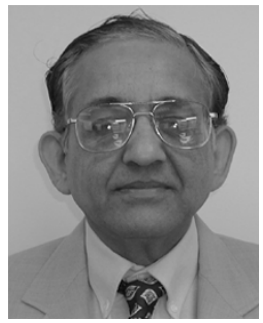

Pawan K. Bhartia received the the M.S. degree in computer science and the Ph.D. degree in physics from Purdue University, West Lafayette, IN.

$\mathrm{He}$ is currently the Project Scientist of NASA's Total Ozone Mapping Spectrometer satellite mission and the U.S. Science Team Leader of the Ozone Monitoring Instrument on EOS Aura. He has over 60 scientific publications, dealing principally with the measurement of the Earth's ozone layer.

Dr. Bhartia has received several NASA awards for his work, including the prestigious William Nordberg Medal in Earth Science from the NASA Goddard Space Flight Center.

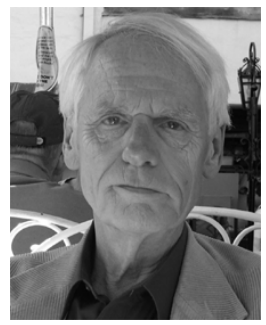

Reinhard Beer received the Ph.D. degree in physics from the University of Manchester, Manchester, U.K., in 1960 .

$\mathrm{He}$ is currently the Principal Investigator for the Tropospheric Emission Spectrometer on the Earth Observing System Aura satellite launched on July 15,2004 . He joined the Jet Propulsion Laboratory, California Institute of Technology, Pasadena, in 1963.

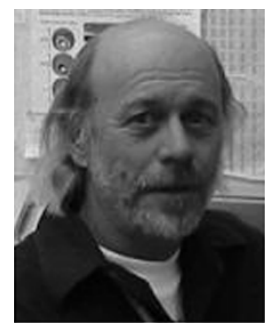

Joe William Waters was born January 12, 1944 in Montgomery County, TN. He received the B.S. and M.S. degrees in 1967, and the Ph.D. degree in 1971, all from the Massachusetts Institute of Technology, Cambridge. His Ph.D. topic, supervised by D.H. Staelin, was on microwave remote sensing of the stratosphere.

He was on the research staff of the MIT Research Laboratory of Electronics from 1971 until 1973, and responsible for retrievals of atmospheric temperature profiles from the Nimbus- 5 Microwave Spectrometer. Since 1973, he has been with the Jet Propulsion Laboratory (JPL), Pasadena, CA. In 1974, he started development of the microwave limb sounding technique and the MLS experiments, which he has led since then. These progressed through experiments on aircraft, balloons, the Upper Atmosphere Research Satellite, and on the Earth Observing System Aura satellite. He is currently a Senior Research Scientist at JPL, and heads research groups in the JPL Science Division and the Instrument and Science Data Systems Division. He is the author of more than 150 peer-reviewed publications.

Dr. Waters has twice been awarded the NASA Exceptional Scientific Achievement Medal.

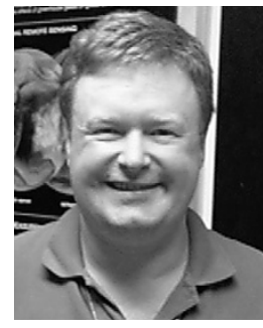

Michael R. Gunson received the Ph.D. degree in theoretical chemistry from Bristol University, Bristol, U.K., in 1983.

Since 1987, he has been with the Jet Propulsion Laboratory, California Institute of Technology, Pasadena, and has worked as a Science Team Member on the Tropospheric Emission Spectrometer, Atmospheric Infrared Sounder, and the Atmospheric Trace Molecule Spectroscopyinstruments. His research interests include atmospheric remote sensing, composition, and chemistry.

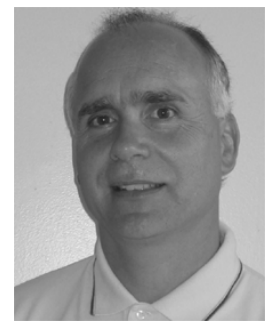

Lucien Froidevaux was born in Zurich, Switzerland. He finished high school in 1973, in Orsay, France. He received the B.A. degree in physics from the University of California, Los Angeles (UCLA), in 1976. As a graduate student, he spent a year at UCLA and a year at the Massachusetts Institute of Technology, Cambridge. Then, he received the Ph.D. degree in earth and planetary sciences at the California Institute of Technology, Pasadena, in 1983.

He has written articles on subjects ranging from Io's torus and Saturn's rings to the modeling of Earth's stratospheric chemistry. From 1983 to 1985 , he was with the Jet Propulsion Laboratory (JPL), Pasadena, CA, under an NRC-NASA Resident Research Associateship award (with C. B. Farmer on the ATMOS experiment). $\mathrm{He}$ is currently a Principal Scientist at JPL, in the Microwave Atmospheric Science Group of the Earth Remote Sensing Science Section, Division of Earth and Space Sciences. Much of his earlier work was as a Co-Investigator on the Upper Atmosphere Research Satellite (UARS) MLS team. He is currently Deputy Principal Investigator for EOS MLS, and has been a Chair of the Aura Validation Working Group since its prelaunch inception. He is the author or coauthor of over 80 peer-reviewed scientific articles.

Dr. Froidevaux has received NASA Group Achievement Awards and a NASA Exceptional Achievement Medal, as well as two Editor's Citations for Excellence in Refereeing for the Journal of Geophysical Research. 


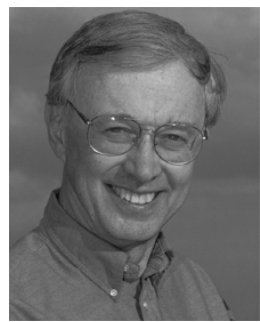

John C. Gille received the B.S. degree in physics from Yale College, Wrexham, U.K., the M.A. degree in physics from Cambridge University, Cambridge, U.K., and the Ph.D. in geophysics from the Massachusetts Insitute of Technology, Cambridge.

$\mathrm{He}$ is currently a Senior Scientist at the National Center for Atmospheric Research, Boulder, $\mathrm{CO}$, and an Adjoint Professor and Senior Research Associate at the University of Colorado, Boulder. He is the U.S. Principal Investigator for the High Resolution Dynamics Limb Sounder on Aura, and the Principal Investigator for the U.S. activities on the Measurements of Pollutants in the Troposphere investigation on Terra. Previously he was the Principal Investigator on the Limb Radiance Inversion Radiometer (on Nimbus 6), the first limb sounder, for which he developed some of the fundamental supporting concepts. Subsequently he was Co-Sensor Scientist on the Limb Infrared Monitor of the Stratosphere on Nimbus 7 and Principal Investigator on the collaborative investigation associated with the Cryogenic Limb Array Emission Spectrometer on the Upper Atmosphere Research Satellite. In addition to his interests in atmospheric remote sensing, he has worked on problems related to radiative transfer in the atmospheres of the Earth and planets, radiative heating rates, and the effect of radiation on fluid dynamics.

Dr. Gille received the NCAR Technology Advancement Award in 1978 and the NASA Exceptional Scientific Achievement Medal in 1982.

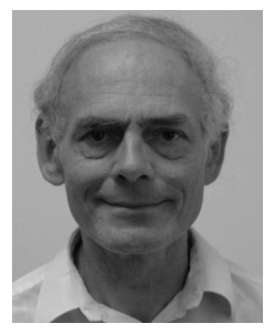

John J. Barnett received his first degree from Cambridge University, Cambridge, U.K., in 1969, and the Dr.Phil. degree in atmospheric physics from Oxford University, Oxford, U.K., in 1973.

$\mathrm{He}$ is currently a Research Lecturer in the Department of Physics, Oxford University. His main research interest is in atmospheric remote sounding. $\mathrm{He}$ is the joint (U.K.) Principal Investigator of the HIRDLS instrument.

Dr. Barnett was the recipient of the Royal Meteorological Society L. F. Richardson Award, the COSPAR William Nordberg Award, and a joint recipient of the WMO Norbert Gerbier-Mumm Ward.

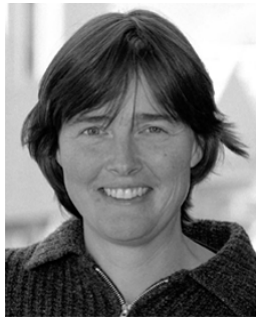

Pieternel F. Levelt received the M.S. degree in physical chemistry and the Ph.D. degree from the Free University of Amsterdam, Amsterdam, The Netherlands, in 1987 and 1992, respectively. Her $\mathrm{Ph} . \mathrm{D}$. work consisted of the development of a XUV spectrometer-based nonlinear optical technique and performing XUV spectroscopy on small diatomic molecules.

In 1993, she started working at the Royal Netherlands Meteorological Institute (KNMI), De Bilt, in the Atmospheric Composition section at the Research Department of KNMI. There, she worked on chemical data assimilation of ozone in two-dimensional and three-dimensional chemistry transport models and on the validation of the European satellite instruments GOME and SCIAMACHY. She was a Member of the Algorithm and Validation subgroups of GOME and SCIAMACHY. She was strongly involved in the validation program of both instruments. Since July 1998, she has been Principal Investigator of the OMI instrument and is responsible for the scientific program of OMI and managing the international OMI Science Team. She is also the Project Manager of the OMI Program at KNMI and responsible for the development of algorithms, validation, and data processing of OMI products and in-flight calibration and operational planning of the OMI instrument. She is managing the OMI team at KNMI consisting of 15 to 35 people. As Principal Investigator, she is advising NIVR on OMI instrument requirements and performance.

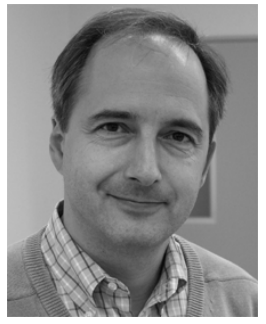

Phil DeCola received the B.A. degree in chemistry and the Ph.D. degree in chemical physics from the University of Pennsylvania, University Park.

$\mathrm{He}$ is currently a Program Scientist for the Aura Mission and for the Atmospheric Composition Focus Area in the NASA Science Mission Directorate, Earth-Sun System Division, Washington, DC. His scientific training and research were in the areas of molecular spectroscopy and condensed phase energy transfer, and he has authored a number of publications in the area of nonlinear spectroscopy and its application to solid-state energy transfer. He also has worked on radiative transfer properties of planetary atmospheres and is now focused on space-based remote sensing of Earth's atmospheric composition. He serves as the Co-Chair of the U.S. Government's Climate Change Science Program Subgroup on Atmospheric Composition.

Dr. DeCola has received the Terra Award in Earth Science, the NASA Exceptional Performance Award for his leadership of atmospheric composition research within NASA, and a National Academy of Sciences Postdoctoral Fellowship. 